\title{
Consumption of tall oil-derived phytosterols in a chocolate matrix significantly decreases plasma total and low-density lipoprotein-cholesterol levels
}

\author{
Jacqueline de Graaf $^{1 *}$, Pernette R. W. de Sauvage Nolting ${ }^{2}$, Marjel van Dam ${ }^{2}$, Elizabeth M. Belsey ${ }^{3}$, \\ John J. P. Kastelein ${ }^{2}$, P. Haydn Pritchard ${ }^{4}$ and Anton F. H. Stalenhoef ${ }^{1}$ \\ ${ }^{1}$ Department of General Internal Medicine, University Medical Centre Nijmegen, Nijmegen, The Netherlands \\ ${ }^{2}$ Department of Vascular Medicine, Academic Medical Centre, Amsterdam, The Netherlands \\ ${ }^{3}$ Department of Statistics, Division of Infectious Diseases, Northwestern University, Chicago, IL, USA \\ ${ }^{4}$ Department of Pathology and Laboratory Medicine, University of British Columbia, Vancouver, Canada
}

(Received 1 October 2001 - Revised 29 May 2002 - Accepted 18 June 2002)

\begin{abstract}
In a randomized, double-blind, placebo-controlled trial we evaluated the effect of dietary chocolates enriched with a wood-based phytosterol-phytostanol mixture, containing $18 \%(\mathrm{w} / \mathrm{w})$ sitostanol, compared with placebo dietary chocolates in seventy subjects with primary hypercholesterolaemia (total cholesterol levels below $8 \mathrm{mmol} / \mathrm{l}$ ). For 4 weeks, participants consumed three servings of the phytosterol-enriched chocolate/d that provided $1.8 \mathrm{~g}$ unesterified phytosterols/d or a placebo chocolate in conjunction with a low-fat, low-cholesterol diet. Plasma total and LDL-cholesterol levels were statistically significantly reduced by $6.4 \%(-0.44 \mathrm{mmol} / \mathrm{l})$ and $10.3 \%(-0.49 \mathrm{mmol} / \mathrm{l})$, respectively, after 4 weeks of phytosterol-enriched-chocolate treatment. Plasma HDL-cholesterol and triacylglycerol levels were not affected. Consumption of phytosterol-enriched chocolates significantly increased plasma lathosterol concentration $(+20.7 \%)$, reflecting an increased endogenous cholesterol synthesis in response to phytosterol-induced decreased intestinal cholesterol absorption. Furthermore, the chocolates enriched with phytosterols significantly increased both plasma sitosterol $(+95.8 \%)$ and campesterol $(+64.1 \%)$ levels, compared with the placebo chocolate group. However, the absolute values of plasma sitosterol and campesterol remained within the normal range, that is, below $10 \mathrm{mg}$ / 1. The chocolates with phytosterols were palatable and induced no clinical or biochemical side effects. These findings indicate that dietary chocolate enriched with tall oil-derived phytosterols $(1.8 \mathrm{~g} / \mathrm{d})$ is effective in lowering blood total and LDL-cholesterol levels in subjects with mild hypercholesterolaemia and thus may be helpful in reducing the risk of CHD in these individuals.
\end{abstract}

Phytosterols: Lipids: Chocolate

Recent studies have convincingly shown that serum total and LDL-cholesterol reduction significantly decreases total and coronary mortality in primary and especially secondary prevention of CHD (Scandinavian Simvastatin Survival Study Group, 1994; Shephard et al. 1995). Dietary modification can reduce cholesterol levels and the risk of CHD, but for a significant portion of the population, treatment with lipid-lowering agents is required for effective cholesterol reduction. There is an urgent clinical need for a low-cost, low-risk intervention that can treat those individuals that have not responded well to dietary modification, and where pharmaceutical intervention is not desirable. Consumption of foods containing phyto- (i.e. plant) sterols has the necessary characteristics to meet that need.

There has been renewed interest in the use of phytosterols for the treatment of hypercholesterolaemia, since they have potent cholesterol-lowering effects, as shown in normo- and hypercholesterolaemic men and women with or without CHD (Miettinen et al. 1995; Gylling et al. 1997; Westrate et al. 1998; Plat \& Mensink, 2000), children (Gylling et al. 1995; Tammi et al. 2000) and diabetics (Gylling \& Meittinen, 1994, 1996). Phytosterols interfere with cholesterol metabolism, especially intestinal cholesterol 
absorption, and consequently reduce serum total cholesterol by approximately $10 \%$ and LDL-cholesterol by $15 \%$, as recently reviewed by Cater (1999), Miettinen \& Gylling (1999), Moghadasian \& Frolich (1999), Law (2000) and Plat \& Mensink, (2001).

Due to the lack of toxicity in man, phytosterols have an important advantage over existing pharmaceutical agents in the potential prevention of atherosclerotic vascular disease. Therapeutically, phytosterols could be positioned after diet modification or used in conjunction with other agents having cholesterol-lowering activity (Blair et al. 2000).

The objective of the present study was to develop a food-based product that lowers undesirable blood cholesterol levels, through the addition of safe, effective and undetectable phytosterols. In the context of a clinical outpatient-based study, it was important that this food be both palatable and easy to consume with each of three meals/d. To address this objective, dietary chocolate containing a phytosterol mixture was administered to study subjects for 4 weeks. Specifically, diets containing chocolate alone were compared with diets containing chocolate supplemented with tall oil-derived sterols. Tall oil-derived phytosterols consist of a proprietary mixture of four phytosterols ( $\beta$-sitosterol, sitostanol, campesterol, campestanol) in the approximate ratio of 60:20:14:3. It was anticipated that the study results would assist in the development of a chocolate that would offer advantages in the control of plasma LDL levels.

The overall objective of the study was to examine whether the addition of a tall oil-derived phytosterol mixture to dietary chocolate results in a reduction in total and LDL-cholesterol levels compared with chocolate alone, in mildly hypercholesterolaemic individuals.

\section{Subjects and methods}

\section{Subjects}

A total of seventy volunteers, including both men and woman, with primary hypercholesterolaemia were recruited by advertisement in local newspapers from inhabitants of Nijmegen, Rotterdam, Amsterdam and Groningen (The Netherlands). To be eligible for enrolment, participants had to meet the following inclusion criteria: age 21-75 years; fasting total cholesterol level between 5.5 and $8.0 \mathrm{mmol} / \mathrm{l}$; fasting LDL-cholesterol level $\geq 3.5 \mathrm{mmol} / \mathrm{l} ;$ triacylglycerol level $<4.0 \mathrm{mmol} / \mathrm{l} ; \mathrm{HDL}$ levels $\geq 0.8 \mathrm{mmol} / \mathrm{l}$ and BMI $<35 \mathrm{~kg} / \mathrm{m}^{2}$. Eligible subjects reported consuming ten or fewer units of alcohol ( 1 unit $=$ $10 \mathrm{ml}$ ethanol)/week. Premenopausal women had to have been surgically sterilized or highly unlikely to conceive, i.e. taking oral contraceptives or with an intra-uterine device in place for 3 months. Exclusion criteria were secondary causes for dyslipidaemia, including a history of diabetes mellitus, hypothyroidism and hepatic or renal impairment, or apolipoprotein phenotype E2/E2. Furthermore, eligible subjects reported not having a current disease or history of malignancy, uncontrolled hypertension, unstable angina or myocardial infarction within 3 months before the study, familial sitosterolaemia, ileal bypass surgery or any gastrointestinal disorder that could affect cholesterol or fat absorption. Except for the phytosterol mixture, no other cholesterol-lowering agents including $\beta$-hydroxy- $\beta$-methylglutaryl-CoA reductase inhibitors, fibrates, and bile-acid resins were to be taken during the study. In the placebo group, ten subjects used other medication including post-menopausal oestrogen therapy $(n 1)$, anti-thrombolytic medication ( $n$ 3), $\beta$-blockers (n 3) and angiotensin-converting-enzyme inhibitors ( $n 3)$, whereas in the phytosterol-enriched group two subjects used $\beta$ blockers, two subjects used an angiotensin II antagonist and one subject used a combination of a $\beta$-blocker and an angiotensin II-antagonist. All concomitant medication was maintained unchanged during the study. The participants were requested to retain their normal lifestyle and continue their standard lipid-lowering diet throughout the trial. The protocol was approved by the ethical committees of the four institutions and written informed consent was obtained from all subjects.

\section{Study design}

The study was a double-blind, randomized, placebo-controlled clinical trial over 4 weeks. The study consisted of three sequential phases: screening (week -4); diet counselling (week -4 to week -1 ); active treatment (week 0 to week 4). After screening, all eligible subjects were enrolled into the study. At the start of the study (week -4) participants were encouraged to continue their standard lipid-lowering diet throughout the trial (American Heart Association step I diet (NCEP, 2001): <30\% total energy/d from fat (maximum $10 \%$ saturated fat) and cholesterol $<300 \mathrm{mg} / \mathrm{d}$ ). The subject received oral and written instructions on the diet by dietitians. Dietary counselling, through expert questioning, took place twice, at week -4 and -1 . At study visits, subjects were asked for possible changes in diet habits.

Baseline plasma lipid and lipoprotein values were measured four times during screening and diet counselling (weeks $-4,-2,-1$ and 0 ). Thereafter, subjects were randomly assigned to receive either three chocolate servings/ $\mathrm{d}$, containing a tall oil-phytosterol mixture (total dosage $1.8 \mathrm{~g} / \mathrm{d}$ ) or three placebo-matched chocolate servings to be consumed with meals for 4 weeks. Blood samples for efficacy and safety measures were obtained at weeks 3 and 4. During the study participants were asked to report any important deviation in lifestyle as well as intercurrent illnesses and use of concomitant medication. Routine blood chemistry (aspartate aminotransferase (ASAT), alanine aminotransferase (ALAT) bilirubin, alkaline phosphatase, glucose, uric acid, urea, creatinine, thyroid stimulating hormone (TSH)), haematology (haemoglobin, packed cell volume, erythrocyte and leucocyte count, platelet count) and urinalysis were performed. All reported or observed clinical adverse effects and clinically significant laboratory adverse effects were recorded. Compliance was monitored by counting the chocolates returned and measured by the ratio of the number of chocolates consumed to the number that should have been consumed between weeks 0 and 4 , i.e. eighty-four chocolates. 
Table 1. Composition of daily dosage of chocolate $(31.5 \mathrm{~g} / \mathrm{d})$

\begin{tabular}{|c|c|c|}
\hline & $\begin{array}{l}\text { Placebo } \\
\text { chocolate }\end{array}$ & $\begin{array}{l}\text { Phytosterol-enriched } \\
\text { chocolate }\end{array}$ \\
\hline \multirow{2}{*}{\multicolumn{3}{|c|}{ Major fatty acids (g/d) }} \\
\hline & & \\
\hline Saturated & 5.9 & $6 \cdot 0$ \\
\hline Palmitic (C16:0) & 3.1 & $3 \cdot 2$ \\
\hline Stearic (C18:0) & $2 \cdot 6$ & $2 \cdot 7$ \\
\hline \multicolumn{3}{|l|}{ Monounsaturated } \\
\hline Oleic (C18:1 cis) & $8 \cdot 0$ & $8 \cdot 1$ \\
\hline \multicolumn{3}{|l|}{ Polyunsaturated } \\
\hline Linoleic (C18: 2cis) & 0.4 & 0.5 \\
\hline Phytosterols $(g / d)$ & 0 & 1.8 \\
\hline Sitosterol & 0 & 1.09 \\
\hline Campesterol & 0 & 0.26 \\
\hline Sitostanol & 0 & 0.37 \\
\hline Campestanol & 0 & 0.06 \\
\hline Carbohydrate $(\mathrm{g} / \mathrm{d})$ & $11 \cdot 8$ & 11.8 \\
\hline Sugar & $9 \cdot 7$ & 9.7 \\
\hline Protein $(g / d)$ & 1.5 & 1.5 \\
\hline Cholesterol (mg/d) & 4.9 & 4.9 \\
\hline
\end{tabular}

\section{Test and control chocolates}

The phytosterols, derived from tall-oil soap, are a proprietary mixture of four phytosterols ( $\beta$-sitosterol, sitostanol, campesterol, campestanol) in the approximate ratio of 60:20:14:3. The mixture contains $18 \%$ (w/w) sitostanol. Some minor phytosterols such as stigmasterol may be present in amounts less than $1 \%$ each of the total mixture. The two chocolate preparations (placebo and phytosterolenriched chocolates) were foil-seal packaged and were indistinguishable in colour, taste, absorbable fat content and energy value. Each chocolate weighed $10.5 \mathrm{~g}$ and contained $260 \mathrm{~kJ}$ (62 kcal) energy. The composition of the chocolates is presented in Table 1. Furthermore, each chocolate contained $4.5 \mathrm{mg} \mathrm{Na}$ and traces of vitamin A $(3.9 \mu \mathrm{g})$, vitamin $\mathrm{C}(0.13 \mathrm{mg}), \mathrm{Ca}(16 \mathrm{mg}), \mathrm{Fe}(0.15 \mathrm{mg})$ and dietary fibre $(0 \cdot 12 \mathrm{~g})$. The non-esterified phytosterolstanol mixture and chocolates were prepared by Forbes Medi-Tech Inc, Vancouver, BC, Canada.

\section{Lipid and lipoprotein analysis: routine blood chemistry and haematology}

Venous blood samples were collected by venepuncture from an antecubital vein after an overnight fast. Plasma and serum were prepared by centrifuging blood for $10 \mathrm{~min}$ at $3000 \mathrm{~g}$. Samples were stored at $-80^{\circ} \mathrm{C}$. A central laboratory (AML, Antwerpen, Belgium) analysed all blood samples for lipid and lipoprotein levels and routine blood chemistry and haematology. Total cholesterol and triacylglycerol levels were measured using the cholesterol Csystem high performance enzymic calorimetric tests CHOD-PAP and GPO-PAP, respectively (Boehringer Mannheim, GmbH, Germany). HDL-cholesterol was measured as described for total cholesterol after precipitation of apolipoprotein B-containing lipoproteins with heparin-manganese. LDL-cholesterol was calculated using the Friedewald formula. Routine blood chemistry and haematology were performed to assess possible adverse effects of phytosterol consumption. Plasma ALAT, $\gamma$-glutamyl transpeptidase
( $\gamma \mathrm{GT})$, ASAT, bilirubin, albumin, glucose, uric acid, urea and creatinine were determined using commercial test kits (Boehringer Mannheim, GmbH, Diagnostica, Germany). Alkaline phosphatase activity was measured in serum. Haemoglobin concentration, leucocyte cell count, erythrocyte cell count, platelet count and calculation of packed cell volume were performed using a Sysmex microcell F-800 bloodcell counter.

\section{Lathosterol and phytosterol measurements}

Serum non-cholesterol sterol levels $(\mu \mathrm{mol} / \mathrm{l})$, including lathosterol (a cholesterol precursor sterol reflecting cholesterol synthesis; Kempen et al. 1988) and phytosterols (stigmasterol, sitostanol, campesterol and sitosterol), were measured using GC following established methodology. Briefly, $0.1 \mathrm{ml}$ plasma was saponified with $\mathrm{KOH}$ for $1 \mathrm{~h}$ at $37^{\circ} \mathrm{C}$. Extracted samples were derivatized with $\mathrm{N}, \mathrm{O}-$ Bis(trimethylsilyl)trifluoracetamide and $1 \%$ trimethylchorosilane and injected into a Varian 3400 gas chromatograph (Sunnyvale, CA, USA) equipped with a capillary column (CP-SIL 19CB FS $25 \times 0.25$ (0.2); Chrompack, Middelburg, The Netherlands) and a data processing system, using flame ionisation as detection and coprostanol as an internal standard. Campesterol, stigmasterol and sitosterol were identified using authenticated standards (Sigma, St. Louis, MO) (Koopman et al. 1987; Hodis et al. 1991). Plasma phytosterols were determined twice from the same sample and the mean value of the two determinations was used in the statistical analysis.

Non-cholesterol sterols in serum are transported in a mixture with cholesterol in lipoproteins, up to $90 \%$, by LDL. Accordingly, concentrations of non-cholesterol sterols usually have positive correlation coefficients with that of cholesterol. To eliminate the effect of changing lipid and lipoprotein levels, the non-cholesterol sterol values are standardized and expressed in terms of $10^{2} \times$ $\mathrm{mmol} / \mathrm{mol}$ cholesterol, that is, in ratios to serum total cholesterol. Non-cholesterol sterols were measured pre(weeks -1 and 0 ) and post-treatment (weeks 3 and 4). The sterol measurements were performed in the lipid research laboratory of the University Medical Centre Nijmegen, The Netherlands.

\section{Statistical methods}

Analyses were conducted on the per-protocol population, defined as subjects with an average LDL-cholesterol at weeks -2 and -1 of $\geq 3.5 \mathrm{mmol} / \mathrm{l}$; less than $15 \%$ variation in LDL-cholesterol between weeks -2 and -1 ; triacylglycerols $<4.0 \mathrm{mmol} / \mathrm{l}$ at each of weeks $-2,-1$ and 0 ; $80 \%$ compliance; no more than $3 \mathrm{~d}$ off treatment before the week 4 visit; week 4 visit no more than 6 weeks after starting treatment.

Subjects randomized to the two treatment groups were compared with respect to information collected at weeks $-2,-1$ and 0 , which occurred before the start of study treatment. This information included demographics, vital signs, findings on physical examination, and laboratory measurements (lipids, haematology, chemistry). The weight, BMI, blood pressure and lipid and lipoprotein values obtained at 
weeks $-2,-1$ and 0 were averaged to obtain a single baseline value. Differences between intervention groups at baseline were evaluated by the $\chi^{2}$ test for categorical variables and by the $t$ test for continuous variables.

The primary efficacy measurements were the changes in plasma total cholesterol and LDL-cholesterol. The outcome variables, including absolute total and LDL-cholesterol levels at weeks 3 and 4 and the absolute and percentage (relative) changes in total and LDL-cholesterol levels from baseline to each post-treatment visit were analysed using analysis of covariance, with treatment group included as the only main effect. The baseline value was included as a covariate in analysis of the post-treatment values and the absolute changes from baseline. The mean post-treatment values (and 95\% CI) presented are least squares means, adjusted for any difference in the baseline value between the two treatment groups.

Similar analyses were performed for the secondary efficacy measurements (triacylglycerol, HDL-cholesterol and LDL:HDL) and non-cholesterol sterol measurements, with the difference that the average of the values obtained at weeks 3 and 4 was used as the post-treatment value.

The measurements made at week 4 were used as the post-treatment values for routine blood and chemistry, weight, BMI and blood pressure. If a measurement was not available at week 4 , the value obtained at week 3 was carried forward. The post-treatment value and change from baseline were compared between treatment groups using analysis of covariance, including the baseline value as a covariate. The significance of the difference from 0 of the change from baseline within each group was determined either by the paired $t$ test or by Wilcoxon's matched pairs signed ranks test, as appropriate.

The proportion of subjects reporting any treatmentemergent adverse event was compared between treatment groups using the $\chi^{2}$ test. Compliance was compared between treatment groups using the Mann-Whitney U test. Statistical analyses were performed using SAS Version 8 (SAS Institute Inc, Cary, NC, USA).

\section{Results}

Subjects

Seventy subjects were enrolled in the two study groups.
One subject randomized to the placebo group discontinued because of an adverse event, and one subject given phytosterol-enriched chocolates withdrew consent after starting consumption of the study product. There was no difference between treatment groups with respect to the proportion of subjects who completed the trial (97\%).

Results presented are based on the per-protocol analysis. In total, eight subjects were excluded from the per-protocol analysis, four in the placebo group and four in the phytosterol-enriched-chocolate group due to more than $15 \%$ variation in LDL between week -2 and -1 ( $n 1$ per group), triacylglycerol levels $\geq 4.0 \mathrm{mmol} / \mathrm{l}$ at any of weeks -2 , -1 or 0 ( $n 1$ per group) and compliance less than $80 \%$ (n 2 per group). At baseline, the placebo group ( $n$ 31) and phytosterol-enriched-chocolate group (n 31) were similar in sex distribution, mean age, BMI and blood pressure (Table 2). All participants had primary hypercholesterolaemia, as reflected by high LDL-cholesterol levels, with no significant difference between the two treatment groups in lipid or lipoprotein variables (Tables 3 and 4). Baseline haematology and chemistry results indicated no significant difference between treatment groups (results not shown).

The chocolates were tolerated well by all subjects and no significant clinical or laboratory safety side effects were observed. There were no reported abnormalities of stool consistency or colour. Compliance was $99.4 \%$ in the placebo group and $96.7 \%$ in the phytosterol-enriched-chocolate group, with no statistically significant difference between treatment groups.

No significant change in BMI was found after treatment $\left(25 \cdot 3(95 \%\right.$ CI $24 \cdot 2,26 \cdot 3) \mathrm{kg} / \mathrm{m}^{2}$ in the placebo group; $25 \cdot 2$ $(95 \%$ CI $24 \cdot 1,26.3) \mathrm{kg} / \mathrm{m}^{2}$ in the phytosterol-enrichedchocolate group). Subjects given phytosterol-enriched chocolates experienced significant decreases in both systolic $(-6.6 \mathrm{mmHg}, \quad P<0.005)$ and diastolic $(-2.4 \mathrm{mmHg}$, $P<0.01)$ blood pressure during treatment. However, there was no significant difference between treatment groups post-treatment.

\section{Effect of treatment on plasma lipid and lipoprotein levels}

The mean absolute total plasma cholesterol and LDLcholesterol levels during the treatment period are presented in Table 3. In the placebo group, total and LDL-cholesterol levels did not change during the study. The phytosterol-

Table 2. Baseline characteristics of the subjects with primary hypercholesterolaemia participating in the placebo-controlled phytosterol-enriched-chocolate study*

(Mean values and $95 \%$ confidence intervals)

\begin{tabular}{|c|c|c|c|c|}
\hline & \multicolumn{2}{|c|}{ Placebo group ( $n$ 31) } & \multicolumn{2}{|c|}{$\begin{array}{l}\text { Phytosterol-enriched- } \\
\text { chocolate group (n 31) }\end{array}$} \\
\hline & Mean & $95 \% \mathrm{Cl}$ & Mean & $95 \% \mathrm{Cl}$ \\
\hline Male: $n(\%)$ & $18(58 \%)$ & & $12(39 \%)$ & \\
\hline Age (years) & $57 \cdot 8$ & $54 \cdot 5,61 \cdot 0$ & $56 \cdot 2$ & $52 \cdot 2,60 \cdot 3$ \\
\hline $\mathrm{BMI}\left(\mathrm{kg} / \mathrm{m}^{2}\right)$ & 25.4 & $24 \cdot 3,26 \cdot 4$ & $25 \cdot 3$ & $24 \cdot 3,26 \cdot 4$ \\
\hline Systolic blood pressure $(\mathrm{mmHg})$ & $130 \cdot 4$ & $125 \cdot 3,135 \cdot 5$ & $132 \cdot 0$ & $126 \cdot 7,137 \cdot 2$ \\
\hline Diastolic blood pressure (mmHg) & 82.5 & $79 \cdot 8,85 \cdot 2$ & 83.4 & $80 \cdot 3,86 \cdot 5$ \\
\hline
\end{tabular}

* For details of the chocolate, see Table 1. Values of BMI and blood pressure are the average of three baseline measurements at weeks $-2,-1$ and 0 . No significant differences between the groups were found. 
enriched-chocolate group experienced statistically significant decreases in both total and LDL-cholesterol levels from baseline at both week 3 and week 4 . The absolute (and relative) change in total cholesterol after treatment with phytosterol-enriched chocolates was $-0.36 \mathrm{mmol} / \mathrm{l}(-5.2 \%$, $P<0.001)$ and $-0.44 \mathrm{mmol} / \mathrm{l}(-6.4 \%, P<0.001)$ at week 3 and week 4, respectively. LDL-cholesterol levels decreased by $0.31 \mathrm{mmol} / 1 \quad(-6.5 \%, P<0.005)$ and $0.49 \mathrm{mmol} / 1(-10.3 \%, P<0.001)$ at week 3 and week 4 , respectively. At both week 3 and week 4, subjects randomized to phytosterol-enriched chocolates had lower total cholesterol and LDL-cholesterol levels, and greater decreases and relative decreases in total and LDL-cholesterol, than subjects given the placebo (all $P<0.005$ ).

Table 4 shows the change in triacylglycerol and HDLcholesterol levels and LDL:HDL in both treatment groups. No significant changes within or differences between treatment groups were found in triacylglycerol or HDL-cholesterol levels. Mean LDL:HDL decreased significantly in the phytosterol-enriched-chocolate group after treatment $(P<0.05)$, whereas no change was found in the placebo group. In addition, the phytosterol-enriched-chocolate group had a lower LDL:HDL post-treatment $(P<0.05)$ and greater absolute and relative decreases in LDL:HDL from baseline $(P<0.05$ and $P<0.005$, respectively) than the placebo group.

\section{Effect of treatment on lathosterol and phytosterols levels}

The effect of treatment on lathosterol and phytosterol concentrations, expressed in both $\mu \mathrm{mol} / \mathrm{l}$ and in $10^{2} \mathrm{mmol} / \mathrm{mol}$ cholesterol, is shown in Table 5. For the lathosterol concentration, there was no difference between the two groups at baseline, and no significant change in lathosterol levels during treatment in the placebo group. Subjects given phytosterol-enriched chocolates experienced a significant relative increase in lathosterol levels and had significantly higher lathosterol levels post-treatment than subjects in the placebo group. No difference between the two groups in the absolute or relative change in lathosterol levels expressed in $\mu \mathrm{mol} / \mathrm{l}$ was found; however, when corrected for the change in cholesterol levels, the phytosterolenriched-chocolate group showed a greater increase in lathosterol level post-treatment than the subjects in the placebo chocolate group.

For both the campesterol and sitosterol values there was no difference between the two groups at baseline. In the placebo group, no significant change in campesterol levels during treatment was found. However, subjects given phytosterol-enriched chocolates experienced significant absolute and relative increases in campesterol levels post-treatment. There were highly significant differences between treatment groups with respect to campesterol levels post-treatment, and in the absolute and relative changes in campesterol levels from baseline (all $P<0 \cdot 001)$. For the sitosterol levels both groups experienced statistically significant absolute and relative increases during treatment, but the changes among the subjects given phytosterol-enriched chocolates were substantially greater than those in the placebo group. There were highly significant differences between treatment groups 
Table 4. Effect of phytosterol-enriched chocolates compared with placebo chocolates on high-density lipoprotein-cholesterol and triacylglycerol (TAG) concentrations and on low-density lipoprotein-cholesterol:high-density lipoprotein-cholesterol in subjects with primary hypercholesterolaemia*

(Mean values and $95 \%$ confidence intervals)

\begin{tabular}{|c|c|c|c|c|c|c|c|c|c|}
\hline & \multirow{2}{*}{$\begin{array}{l}\text { Treatment } \\
\text { group }\end{array}$} & \multicolumn{2}{|c|}{$\begin{array}{c}\text { Baseline } \\
(n 31) \dagger\end{array}$} & \multicolumn{2}{|c|}{$\begin{array}{l}\text { Post-treatment } \\
\qquad(\text { n 31) } \ddagger\end{array}$} & \multicolumn{2}{|c|}{$\begin{array}{l}\text { Change } \\
(\%) \S\end{array}$} & \multirow[b]{2}{*}{$P \|$} & \multirow[b]{2}{*}{$P q$} \\
\hline & & Mean & $95 \% \mathrm{Cl}$ & Mean & $95 \% \mathrm{Cl}$ & Mean & $95 \% \mathrm{Cl}$ & & \\
\hline \multirow[t]{2}{*}{$\mathrm{HDL}(\mathrm{mmol} / \mathrm{l})$} & Placebo & 1.46 & $1.33,1.58$ & $1 \cdot 36$ & $1.29,1.42$ & -2.6 & $-8 \cdot 0,2 \cdot 9$ & $>0.05$ & \multirow[t]{2}{*}{$>0.05$} \\
\hline & Phytosterol & $1 \cdot 33$ & $1.21,1.45$ & 1.37 & $1.31,1.44$ & 0.1 & $-5.4,5.6$ & $>0.05$ & \\
\hline \multirow[t]{2}{*}{ LDL:HDL } & Placebo & 3.35 & $3.04,3.65$ & 3.59 & $3.38,3 \cdot 80$ & $5 \cdot 3$ & $-0.6,11 \cdot 2$ & $>0.05$ & \multirow[t]{2}{*}{$<0.05$} \\
\hline & Phytosterol & 3.67 & $3.36,3.97$ & $3 \cdot 24$ & $3.03,3.45$ & -7.2 & $-13 \cdot 1,-1 \cdot 4$ & $<0.05$ & \\
\hline 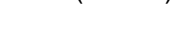 & Phytosterol & 1.60 & $1.38,1.82$ & 1.53 & $1.28,1.79$ & 1.4 & $-7 \cdot 8,10 \cdot 5$ & $>0.05$ & $>0.05$ \\
\hline
\end{tabular}

${ }^{*}$ For details of subjects, chocolates and procedures, see Tables 1 and 2 and p. 480.

† Baseline values of all parameters are the average of three measurements (weeks $-2,-1$ and 0 ).

$\ddagger$ Post-treatment values represent the mean of two measurements (weeks 3 and 4 ).

$\S$ Change (\%) is the mean of the individual percentage change.

$\| P$ value for the within-treatment group (Wilcoxon signed ranks test on absolute changes from baseline (similar values for both week 3 and week 4 )).

I $P$ value for the between-treatment groups (analysis of covariance of post-treatment values)

with respect to sitosterol levels post-treatment, and in the absolute and relative changes in sitosterol levels from baseline (all $P<0.001)$. Stigmasterol and sitostanol were not detectable in plasma.

\section{Discussion}

This randomized, double-blind, placebo-controlled trial demonstrates that a tall oil-derived phytosterol mixture, containing $18 \%(\mathrm{w} / \mathrm{w})$ sitostanol, incorporated into a dietary chocolate consumed three times a day with meals, effectively reduces plasma total and LDL-cholesterol concentrations in mildly hypercholesterolaemic subjects. In the phytosterol-enriched-chocolate group the mean LDLcholesterol level was reduced by $0.49 \mathrm{mmol} / \mathrm{l}(10.3 \%)$. The reduction in LDL-cholesterol produced by the phytosterol ester mixture was already evident after 3 weeks of consumption and even further decreased after 4 weeks.

In agreement with other studies phytosterols did not affect HDL-cholesterol and triacylglycerol concentrations (Jones et al. 1999; Moghadasian \& Frolich, 1999). Due to the unchanged HDL-cholesterol concentration, the phytosterol-enriched chocolates changed LDL-cholesterol:HDL cholesterol in a favourable way.

The phytosterol-enriched chocolates were palatable and well-tolerated, which is consistent with safety data from previous studies.

Phytosterols lower serum cholesterol concentrations extrinsically by reducing the absorption of cholesterol from the gut by competing for the limited space for cholesterol in mixed micelles, which deliver mixtures of lipids for absorption into the mucosal cells (Lees et al. 1977; Mattson et al. 1982; Heinemann et al. 1993; Gylling et al. 1997). The efficacy of the various phytosterols in lowering circulating lipid concentration was shown previously for both unsaturated (sterol) (Lees et al. 1977; Westrate et al. 1998) and saturated (stanol) phytosterols (Miettinen et al. 1995; Gylling et al. 1995; Jones et al. 1998) either esterified or non-esterified to fatty acids (for reviews, see Moghadasian \& Frolich, 1999; Law, 2000).
The most predominant phytosterols and phytostanols are sitosterol, campesterol, stigmasterol and sitostanol and campestanol, respectively. Previous studies have suggested that phytosterols differ from phytostanols as the latter are virtually unabsorbable $(<1 \%)$ in the intestine, whereas $4-5 \%$ of phytosterols are absorbed (Heinemann et al. 1993; Gylling \& Meittinen, 1994). It has been suggested that the intestinal absorbability of phytosterols and stanols is inversely related to its inhibiting effects on cholesterol absorption. So, it was generally believed that phytostanols are more effective in reducing plasma cholesterol than phytosterols. However, recent literature shows that both serum plantstanol and sterol concentration increase with consumption of phytosterols (Hallikainen et al. 2000). In line with this observation, randomised comparisons in four trials show no difference in the cholesterol-lowering capacity of either sterols or stanols (Westrate et al. 1998; Hallikainen et al. 2000; Jones et al. 2000; Normen et al. 2000), indicating that a mixture of phytosterols and stanols may be as effective as stanols alone.

In the present study a phytosterol mixture derived from tall oil was used in which the two main components were $\beta$-sitosterol and sitostanol. We chose to use a sterol-stanol mixture above a single entity for two main reasons. First, sitostanol accounts for about $20 \%$ of the total mixture, potentially the most potent inhibitor of cholesterol uptake from the intestine. Despite having only about 0.25 of the amount of sitostanol as a sitostanyl ester preparation, our phytosterol ester mixture has a cholesterol-lowering effect at a dosage of $1.8 \mathrm{~g} / \mathrm{d}$. So, the amount of sitostanol in our mixture is sufficient for a significant cholesterollowering effect. Second, there is a very significant cost advantage to using a mixture over the single entity; this is particularly important if phytosterols are to be used as food additives.

It has been suggested that the use of phytostanyl esters for cholesterol lowering is safer than the use of phytosterol esters because the latter may cause a marked increase in serum phytosterols in individuals with high sterol absorption efficiency, a condition resembling atherogenic 
Table 5. Effect of phytosterol-enriched chocolates compared with placebo chocolate on the plasma cholesterol precursor lathosterol and phytosterol concentrations in subjects with primary hypercholesterolaemia*

(Mean values and $95 \%$ confidence intervals)

\begin{tabular}{|c|c|c|c|c|c|c|c|c|c|}
\hline & & \multicolumn{2}{|c|}{ Baseline† } & \multicolumn{2}{|c|}{ Post-treatment } & \multicolumn{2}{|c|}{ Change $(\%) \S$} & \multirow[b]{2}{*}{$P \|$} & \multirow[b]{2}{*}{$P q$} \\
\hline & & Mean & $95 \% \mathrm{Cl}$ & Mean & $95 \% \mathrm{Cl}$ & Mean & $95 \% \mathrm{Cl}$ & & \\
\hline Lathosterol $\mu \mathrm{mol} / / \mathrm{l}$ serum & $\begin{array}{l}\text { Placebo chocolates } \\
\text { Phytosterol-enriched chocolates }\end{array}$ & $\begin{array}{l}6.06 \\
6.96\end{array}$ & $\begin{array}{l}4.99,7.14 \\
5.898 .04\end{array}$ & $\begin{array}{l}6.78 \\
7.21\end{array}$ & $\begin{array}{l}6.24,7.32 \\
6.687 .75\end{array}$ & $\begin{array}{r}5 \cdot 1 \\
13 \cdot 4\end{array}$ & $\begin{array}{r}-2 \cdot 9,13 \cdot 1 \\
5 \cdot 421.4\end{array}$ & $\begin{array}{l}>0.05 \\
<0.05\end{array}$ & $<0.05$ \\
\hline Campesterol $\mu \mathrm{mol} / / \mathrm{l}$ serum & Placebo chocolates & $13 \cdot 25$ & $11.52,14.98$ & $12 \cdot 77$ & $11.93,13.62$ & $\begin{array}{r}6 \cdot 6 \\
538\end{array}$ & $-3 \cdot 7,17 \cdot 0$ & $>0.05$ & $<0.001$ \\
\hline Sitosterol $\mu \mathrm{mol} / / \mathrm{l}$ serum & $\begin{array}{l}\text { Phytosterol-enriched chocolates } \\
\text { Placebo chocolates } \\
\text { Phytosterol-enriched chocolates }\end{array}$ & $\begin{array}{r}11.35 \\
8.96 \\
7.97\end{array}$ & $\begin{array}{l}9 \cdot 62,13 \cdot 08 \\
7.82,10 \cdot 10 \\
6 \cdot 83,9 \cdot 11\end{array}$ & $\begin{array}{r}17.80 \\
9.25 \\
14.62\end{array}$ & $\begin{array}{r}16 \cdot 95,18 \cdot 64 \\
8 \cdot 47,10 \cdot 03 \\
13 \cdot 84,15 \cdot 40\end{array}$ & $\begin{array}{l}53 \cdot 8 \\
15 \cdot 0 \\
83 \cdot 1\end{array}$ & $\begin{array}{r}43 \cdot 5,64 \cdot 2 \\
-0.9,30 \cdot 9 \\
67 \cdot 2,99 \cdot 0\end{array}$ & $\begin{array}{l}<0.001 \\
<0.05 \\
<0.001\end{array}$ & $<0.001$ \\
\hline Lathosterol $10^{2} \mathrm{mmol} / \mathrm{mol}$ cholesterol & $\begin{array}{l}\text { Placebo chocolates } \\
\text { Phytosterol-enriched chocolates }\end{array}$ & $\begin{array}{r}91.4 \\
102.8\end{array}$ & $\begin{array}{l}77 \cdot 2,105 \cdot 6 \\
88 \cdot 6,117 \cdot 0\end{array}$ & $\begin{array}{l}101.0 \\
115.5\end{array}$ & $\begin{array}{r}93 \cdot 6,108 \cdot 3 \\
108 \cdot 2,122 \cdot 8\end{array}$ & $\begin{array}{r}4.8 \\
20.7\end{array}$ & $\begin{array}{r}-2 \cdot 7,12 \cdot 4 \\
13.2,28 \cdot 3\end{array}$ & $\begin{array}{l}>0.05 \\
<0.001\end{array}$ & $<0.01$ \\
\hline Campesterol $10^{2} \mathrm{mmol} / \mathrm{mol}$ cholesterol & $\begin{array}{l}\text { Placebo chocolates } \\
\text { Phytosterol-enriched chocolates }\end{array}$ & $\begin{array}{l}200 \cdot 8 \\
169 \cdot 4\end{array}$ & $\begin{array}{l}175 \cdot 5,226 \cdot 1 \\
144 \cdot 1,194 \cdot 7\end{array}$ & $\begin{array}{l}192 \cdot 1 \\
283 \cdot 6\end{array}$ & $\begin{array}{l}179 \cdot 9,204 \cdot 3 \\
271 \cdot 4,295 \cdot 8\end{array}$ & $\begin{array}{r}5.5 \\
64.1\end{array}$ & $\begin{array}{l}-4 \cdot 1,15 \cdot 1 \\
54 \cdot 5,73 \cdot 7\end{array}$ & $\begin{array}{l}>0.05 \\
<0.001\end{array}$ & $<0.001$ \\
\hline Sitosterol $10^{2} \mathrm{mmol} / \mathrm{mol}$ cholesterol & $\begin{array}{l}\text { Placebo chocolates } \\
\text { Phytosterol-enriched chocolates }\end{array}$ & $\begin{array}{l}135 \cdot 9 \\
118 \cdot 8\end{array}$ & $\begin{array}{l}119 \cdot 4,152 \cdot 4 \\
102 \cdot 3,135 \cdot 3\end{array}$ & $\begin{array}{l}200.0 \\
139.5 \\
231.9\end{array}$ & $\begin{array}{l}128 \cdot 2,150 \cdot 9 \\
220 \cdot 5,243 \cdot 3\end{array}$ & $\begin{array}{l}13 \cdot 4 \\
95 \cdot 8\end{array}$ & $\begin{array}{l}-1 \cdot 8,28 \cdot 7 \\
80 \cdot 6,111 \cdot 0\end{array}$ & $\begin{array}{l}<0.001 \\
<0.001\end{array}$ & $<0.001$ \\
\hline
\end{tabular}

"For detalls of subjects, chocolates and procedures, see Tables 1 and 2 and p. 480.

T. Baseline values of all parameters are the average of two measurements (week -1 and 0 ).

$\S$ Change $(\%)$ is the mean of the individual percentage change.

$\| P$ value for the within-treatment group (Wilcoxon signed ranks test on absolute changes from baseline).

ๆ $P$ value for the between-treatment groups (analysis of covariance of post-treatment values). 
phytosterolaemia or sitosterolaemia (Lutjohann \& von Bergmann, 1997). In the present study, we showed that $1.8 \mathrm{~g}$ tall oil-derived phytosterols/d significantly increased plasma sitosterol and campesterol concentrations by $95.8 \%$ and $64.1 \%$, respectively. This high relative increase in phytosterol concentration has also been reported by Westrate et al. (1998) who showed that consumption of $3.24 \mathrm{~g}$ phytosterols/d increased serum sitosterol and campesterol levels by an average of $40 \%$ and $70 \%$, respectively. In addition, recently, Jones et al. (2000) showed an increase of $32.5 \%$ and $71.6 \%$ in sitosterol and campesterol levels, respectively, after 3 weeks of phytosterol ester diet $(1.84 \mathrm{~g} / \mathrm{d})$.

Because extremely high blood levels of phytosterols have been associated with atherosclerosis in subjects homozygous for familial phytosterolaemia the lowest serum levels of sterols might be desirable. In the general population, given a dietary intake of $160-360 \mathrm{mg}$ phytosterols/d, reported serum levels of sitosterol are 3.0$17 \mathrm{mg} / \mathrm{l}$ (Miettinen et al. 1990; Gluck et al. 1991; Stalenhoef et al. 2001). This wide range in a normal population suggests considerable individual variability in the handling of various phytosterols. In a recent review of the genetic basis of sitosterolaemia (Lee et al. 2001) it is reported that phytosterol concentrations in control subjects are in general less than $10 \mathrm{mg} / \mathrm{l}$, whereas homozygous patients with sitosterolaemia have values greater than $80 \mathrm{mg} / \mathrm{l}$ up to $600 \mathrm{mg} / \mathrm{l}$. Heterozygous carriers for sitosterolaemia have values higher than $10 \mathrm{mg} / \mathrm{l}$ but none higher than $20 \mathrm{mg} / \mathrm{l}$ and are otherwise biochemically and clinically healthy.

In our study the sitosterol concentration increased from an average of $3.5 \mathrm{mg} / \mathrm{l}$ to a maximum of $6.1 \mathrm{mg} / \mathrm{l}$, still within the normal range reported among healthy control subjects. Indeed, the sitosterol concentration in serum or in lipoprotein cholesterol mixtures that is needed for enhanced development of atheromatosis is not known and further studies on the effect of variability in phytosterol concentration within the normal range on atherosclerosis are needed.

The inhibition of intestinal cholesterol absorption by phytosterols stimulates de novo hepatic cholesterol synthesis. The cholesterol synthesis rate can be reflected by measuring serum cholesterol precursor lathosterol (Kempen et al. 1988). We have shown that lathosterol concentration is increased by phytosterol treatment in accordance with the literature (Gylling \& Meittinen, 1994, 1997; Jones et al. 2000). So, the inhibition of intestinal cholesterol absorption by phytosterols is accompanied by a compensatory increase in cholesterol synthesis. However, the reduced absorption lowers serum cholesterol despite the compensatory increase in cholesterol synthesis.

Subjects with mild hypercholesterolaemia are recommended to eat foods low in saturated fat and cholesterol, as described in the American Heart Association step I diet. A limitation in the use of chocolate as a vehicle for phytosterols is the intake of extra energy $(779 \mathrm{~kJ}$ $(186 \mathrm{kcal}) / \mathrm{d})$ with $72 \%$ energy from fat, $40 \%$ as saturated fat. So, assuming an energy requirement of 50-year-old subjects of $10468 \mathrm{~kJ}(2500 \mathrm{kcal}) / \mathrm{d}$, the daily chocolate intake provides approximately $19 \%$ of the total fat recom- mendation and $24 \%$ of the saturated fat recommendation. In the present study the adherence to the diet was not recorded by food records and/or nutrition analysis. Most likely, the chocolates increased the total and saturated fat intake, which is not desirable in mildly hypercholesterolaemic subjects on a low-fat, low-cholesterol diet. The potentially increased intake of energy and total and saturated fat did not result in a change in body weight and/or an increase in total and LDL-cholesterol levels in the placebo group in this short-term study. However, we recommend that longterm use of phytosterol-enriched chocolates should be accompanied by dietary advice to replace energy and normal daily fat intake by the same amount provided by the chocolates.

The cholesterol and fat intake may affect the cholesterollowering effect of phytosterols (Mattson et al. 1982; Denke, 1995). However, in three recent randomised trials of stanol margarine in which participants were on lowfat, low-cholesterol diets, the reductions in serum concentrations of LDL-cholesterol were similar to those found in other trials in which the intake of dietary fat was higher (Hallikainen \& Uusitupa, 1999; Jones et al. 1999; Hallikainen et al. 2000). Furthermore, plant stanols were equally effective in patients taking statins who had mean LDL-cholesterol concentrations of only $2.9 \mathrm{mmol} / \mathrm{l}$ (Gylling et al. 1997). Therefore, the total amount of cholesterol and fat in the diet, and its fatty acid composition, is not a major determinant of the plasma cholesterol-lowering effects of plant sterols and stanols. This is presumably due to the fact that not only dietary cholesterol but also biliary cholesterol absorption is inhibited. In the present study, the participants showed a significant decrease in total and LDL-cholesterol in response to phytosterol intake in dietary chocolate compared with dietary chocolate alone, in conjunction with a low-fat, low-cholesterol diet. However, the study was not designed to evaluate the effect of fat intake on the cholesterol-lowering potential of phytosterols.

Phytosterols have been incorporated into various kinds of foods, now known as functional foods, designed to enhance health or contribute to the reduction of a specific disease risk (Diplock et al. 1999; de Graaf \& Stalenhoef, 2000). Because fats are needed to solubilise phytosterol esters, margarines are an ideal vehicle for them, although cream cheese, salad dressing and yoghurt are also used. Mixtures of non-esterified sterols and stanols have the advantage that they can be dispersed in lower-fat-containing foods. Recently, functional foods containing phytosterol mixtures have been recommended in the National cholesterol education program guidelines (Expert Panel on Detection, Evaluation and Treatment of High Blood Cholesterol in Adults, 2001) as the next step after dietary advice to bridge the gap before drug therapy is initiated. The development of various kinds of foods containing phytosterols acknowledges the individual variability in taste and food preference and will contribute to increased availability of various phytosterol-enriched foods eaten by most of the population. We have now shown that tall oil phytosterol consumption suspended in a dietary chocolate favourably alters lipid and lipoprotein levels in mildly hypercholesterolaemic subjects.

The reduction of LDL-cholesterol by approximately $10 \%$ during consumption of a mixture of phytosterols in 
chocolates would be expected to decrease coronary events by $20-40 \%$ (Law et al. 1994), depending on the length of the consumption period. However, the potential added costs for this functional food could limit consumption in the general population. As stanols and sterols become less expensive, their introduction into the food chain will make them an important innovation in the primary prevention of heart disease. Post-marketing surveillance of this functional food remains obligatory to control long-term safety and efficacy.

We conclude that dietary chocolates enriched with tall oil-derived phytosterols $(1.8 \mathrm{~g} / \mathrm{d})$ are a suitable strategy to reduce serum cholesterol and LDL concentrations in mildly hypercholesterolaemic subjects.

\section{Acknowledgements}

The authors wish to thank Magda Hectors of the Lipid Research Laboratory, University Hospital Nijmegen, The Netherlands for expert technical assistance.

\section{References}

Blair SN, Capuzzi DM, Gottlieb SO, Nguyen T, Morgan JM \& Cater NB (2000) Incremental reduction of serum total cholesterol and low-density lipoprotein cholesterol with the addition of plant stanol ester-containing spread to statin therapy. American Journal of Cardiology 86, 46-52.

Cater NB (1999) Historical and scientific basis for the development of plant stanol ester foods as cholesterol lowering agents. European Heart Journal 1, S36-S44.

de Graaf J \& Stalenhoef AFH (2000) The use of margarine with added phytosterols as functional food. Nederlands Tijdschrift voor Geneeskunde 144, 918-921.

Denke MA (1995) Lack of efficacy of low-dose stiostanol therapy as an adjunct to a cholesterol-lowering diet in men with moderate hypercholesterolemia. American Journal of Clinical Nutrition 61, 392-396.

Diplock AT, Agget PJ, Ashwell M, Bornet F, Fern EB \& Roberfroid MB (1999) Scientific concepts of functional foods in Europe: consensus document. British Journal of Nutrition 91 , S1-S27.

Expert Panel on Detection, Evaluation and Treatment of High Blood Cholesterol in Adults (2001) Executive summary of the third report of the national cholesterol education program (NCEP) expert panel on detection, evaluation, and treatment of high blood cholesterol in adults (adult treatment panel III). Journal of the American Medical Association 285, 2486-2497.

Gluck CJ, Speirs J, Tracy T, Streicher P, Illig E \& VanderGrift J (1991) Relationships of serum plant sterols (phytosterols) and cholesterol in 595 hypercholesterolemic subjects, and familial aggregation of phytosterols, cholesterol, and premature coronary heart disease in hypercholesterolemic probands and their first-degree relatives. Metabolism 40, 842-848.

Gylling H \& Miettinen TA (1994) Serum cholesterol and lipoprotein metabolism in hypercholesterolemic NIDDM patients before and during sitostanol ester margarine treatment. Diabetologia 37, 773-780.

Gylling H \& Miettinen TA (1996) Effects of inhibiting cholesterol absorption and synthesis on cholesterol and lipoprotein metabolism in hypercholesterolemic non-insulin-dependent diabetic men. Journal of Lipid Research 37, 1776-1785.

Gylling H, Radhakrishnan R \& Miettinen TA (1997) Reduction of serum cholesterol in postmenopausal women with previous myocardial infarction and cholesterol malabsorption induced by dietary sitostanol ester margarine. Women and dietary sitostanol. Circulation 96, 4226-4231.

Gylling H, Siimes MA \& Miettinen TA (1995) Sitostanol ester margarine in dietary treatment of children with familial hypercholesterolemia. Journal of Lipid Research 36, 1807-1812.

Hallikainen MA, Sarkkinen ES, Gylling H, Erkkila AT \& Uusitupa MIJ (2000) Comparison of the effects of plant sterol ester and plant stanol ester-enriched margarines in lowering serum cholesterol concentrations in hypercholesterolemic subjects on a low-fat diet. European Journal of Clinical Nutrition 54, 715-725.

Hallikainen MA, Sarkkinen ES \& Uusitupa MIJ (2000) Plant stanol esters affect serum cholesterol concentrations of hypercholesterolemic men and women in a dose-dependent manner. Journal of Nutrition 130, 767-776.

Hallikainen MA \& Uusitupa MIJ (1999) Effects of 2 low-fat stanol ester-containing margarines on serum cholesterol concentrations as part of a low-fat diet in hypercholesterolemic subjects. American Journal of Clinical Nutrition 69, 403-410.

Heinemann T, Axtmann G \& von Bergmann K (1993) Comparison of intestinal absorption of cholesterol with different plant sterols in man. European Journal of Clinical Investigation 23, 827-831.

Hodis HN, Crawford DW \& Sevanian A (1991) Cholesterol feeding increases plasma and aortic tissue cholesterol oxide levels in parallel: further evidence for the role of cholesterol oxidation in atherosclerosis. Atherosclerosis 89, 117-126.

Jones PJ, Howell T, MacDougall DE, Feng JY \& Parsons W (1998) Short-term administration of tall oil phytosterols improves plasma lipid profiles in subjects with different cholesterol levels. Metabolism 47, 751-756.

Jones PJ, Ntanios FY, Raeini-Sarjaz M \& Vanstone CA (1999) Cholesterol-lowering efficacy of a sitostanol-containing phytosterol mixture with a prudent diet in hyperlipidemic men. American Journal of Clinical Nutrition 69, 1144-1150.

Jones PJ, Raeini-Sarjaz M, Ntanios FY, Vanstone CA, Feng JY \& Parsons WE (2000) Modulation of plasma lipid levels and cholesterol kinetics by phytosterol versus phytostanol esters. Journal of Lipid Research 41, 697-705.

Kempen HJM, Glatz JFC, Gevers Leuven JA, van der Voort HA \& Katan MB (1988) Serum lathosterol concentration is an indicator of whole-body cholesterol synthesis in humans. Journal of Lipid Research 29, 1149-1155.

Koopman BJ, van der Molen JC, Wolters BG \& van der Pas JB (1987) Determination of some hydroxycholesterols in human serum samples. Journal of Chromatology 416, 1-13.

Law M (2000) Plant sterol and stanol margarines and health. British Medical Journal 320, 861-864.

Law MR, Wald N \& Thompson SG (1994) By how much and how quickly does reduction in serum cholesterol concentration lower risk of ischemic heart disease? British Medical Journal 308, 367-373.

Lee M, Lu K \& Patel SB (2001) Genetic basis of sitosterolemia. Current Opinion in Lipidology 12, 141-149.

Lees AM, Mok HY, Lees RS, McCluskey MA \& Grundy SM (1977) Plant sterols as cholesterol-lowering agents: clinical trials in patients with hypercholesterolemia and studies of sterol balance. Atherosclerosis 28, 325-338.

Lutjohann D \& von Bergmann K (1997) Phytosterolaemia: diagnosis, chracterization and therapeutical approaches. Annals of Medicine 29, 181-184.

Mattson FH, Grundy SM \& Crouse JR (1982) Optimizing the effect of plant sterols on cholesterol absorption in man. American Journal of Clinical Nutrition 35, 697-700. 
Miettinen TA \& Gylling H (1999) Regulation of cholesterol metabolism by dietary plant sterols. Current Opinion in Lipidology 10, 9-14.

Miettinen TA, Puska P, Gylling H, Vanhanen H \& Vartiainen E (1995) Reduction of serum cholesterol with sitostanol-ester margarine in a mildly hypercholesterolemic population. New England Journal of Medicine 333, 1308-1312.

Miettinen TA, Tilvis RS \& Kesaniemi YA (1990) Serum plant sterols and cholesterol precursors reflect cholesterol absorption and synthesis in volunteers of a randomly selected male population. American Journal of Epidemiology 131, 20-31.

Moghadasian MH \& Frohlich JJ (1999) Effects of dietary phytosterols on cholesterol metabolism and atherosclerosis: clinical and experimental evidence. American Journal of Medicine 107, 588-594.

National Cholesterol Education Program (NCEP) (2001) Executive summary of the 3rd report of the NCEP expert panel on detection, evaluation and treatment of high blood cholesterol in adults (adult treatment panel III). Journal of American Medical Association 285, 2486-2497.

Normen L, Dutta P, Lia A \& Andersson H (2000) Soy sterol esters and b-sitostanol ester as inhibitors of cholesterol absorption in human small bowel. American Journal of Clinical Nutrition 71, 908-913.

Plat J \& Mensink RP (2000) Vegetable oil based versus wood based stanol ester mixtures: effects on serum lipids and hemostatic factors in non-hypercholesterolemic subjects. Atherosclerosis 148, 101-112.
Plat J \& Mensink RP (2001) Effect of plant sterols and stanols on lipid metabolism and cardiovascular risk. Nutrition Metabolism and Cardiovascular Diseases 11, 31-40.

Scandinavian Simvastatin Survival Study Group (1994) Randomised trial of cholesterol lowering in 4444 patients with coronary heart disease: the Scandinavian Simvastatin Survival Study (4S). Lancet 344, 1301-1307.

Shephard J, Cobbe SM, Ford I, Isles CG, Lorimar AR, Macfarlane W, McKillop JH \& Packard CJfor the West of Scotland Coronary (1995) Prevention Study Group Prevention of coronary heart disease with pravastatin in men with hypercholesterolemia. New England Journal of Medicine 333, 1301-1307.

Stalenhoef AFH, Hectors M \& Demacker PNM (2001) Effect of plant sterol-enriched margarine on plasma lipids and sterols in subjects heterozygous for phytosterolaemia. Journal of Internal Medicine 249, 163-166.

Tammi A, Ronnemaa T, Gylling H, Rask-Nissila L, Viikari J, Tuominen J, Pulkki K \& Simell O (2000) Plant stanol ester margarine lowers serum total and low-density lipoprotein cholesterol concentrations of healthy children: the STRIP project. Special Turku Coronary Risk Factors Intervention Project. Journal of Pediatrics 136, 503-510.

Westrate JA \& Meijer GW (1998) Plant-sterol-enriched margarines and reduction of plasma total and LDL-cholesterol concentrations in normocholesterolemic and mildly hypercholesterolemic subjects. European Journal of Clinical Investigation $\mathbf{5 2}, 334-343$. 